\title{
PROPERTIES OF LIME-CEMENT PLASTERS INCORPORATING CERAMIC POWDER
}

\author{
M. ČÁCHOVÁ, D. KOŇÁKOVÁ, E. VEJMELKOVÁ, E. BARTOŇKOVÁ, M. KEPPERT \& R. ČERNÝ \\ Department of Materials Engineering and Chemistry, Faculty of Civil Engineering, Czech Technical \\ University in Prague, Czech Republic
}

\begin{abstract}
The effects of ceramic powder, a waste material, on the properties of lime-cement plasters were investigated in this article. The influence of the addition of the pozzolana as a supplementary cementitious material on mechanical and thermal properties of the studied materials was assessed in relation to its basic physical properties and pore structure characterization. Investigated parameters were bulk density, matrix density, open porosity, pore-size distribution, compressive strength, tensile strength, thermal conductivity and specific heat capacity. The results revealed the densifying effect of the pozzolana on the plaster microstructure as the open porosity decreased and bulk density rose to binder replacement level. Although the mean diameter of pores for plasters with higher amount of pozzolana was slightly higher, the volume of pores was lower. The presence of ceramic powder also showed a positive effect on the mechanical properties of plasters. Both compressive and tensile strength rose with increasing replacement ratio. Varying porosities were reflected in the increasing trend of thermal conductivity with rising binder replacement level. On the contrary, specific heat capacity showed the lower values the higher the amount of pozzolana.

Keywords: basic physical properties, cement, ceramic powder, lime, plaster, pore system, pozzolana, thermal properties.
\end{abstract}

\section{INTRODUCTION}

Plaster often puts the finishing touches to a building structure from the point of view of aesthetics and technologic aspect as well. In the past plasters could have served as a reflection of society and human evolution. They showed a historical heterogeneity of societies, traditions and also a mixing of cultures. However, development of plaster mixtures was not so clear and straightforward as we could think at the first sight. General idea was given by an invariable system of the mortar mixture (cement, filler and water), but every culture modified something, according to its difference and geographical location. Until 19th century three species of cement were most frequently used for mortar preparation: clay, lime and gypsum. In twenties of 20th century lime mortars were modified by Portland cement or cement were used as a single-binding agent. Except for classic sand, also volcanic rocks, fly ash, brick dust, plant fibres or animal hair were used as a filler. Different ingredients for example: urine, blood, eggs, fruit juices or beer were gradually added to mortar mixtures. Technological development permanently continues, but in modern time, main requirements relate to the economy and ecology of building materials. We are able to see progressive redirection from classic building techniques and alternative financial and ecological advantageous solutions are looked for. In the field of mortars for plastering it means especially replacement of lime and cement by using waste materials. The paper deals with the possibility of recycling ceramic dust as a component in lime-cement plasters. Many studies have proven the suitability of finely crushed bricks for plaster mixtures. Finely crushed brick dust contains pozzolanic-active particles, which help with formation of better binding bonds. Waste material from brickyards could become a common part of plasters [1]. 
In previous papers $[2,3]$ the utilization of brick waste as a pozzolanic component of pure lime-based mortars and plasters were studied. The goal of this paper is to find suitable proportional binder replacement in blended plaster mixtures. All used methods of measuring and evaluation is described and according to obtained results examined parameters are compared. In this study, six plasters with replacement level from $10 \%$ to $50 \%$ of both lime and cement by ceramic brick powder are studied.

\section{MATERIALS}

The composition of studied plasters is shown in Table 1. The lime-based plaster contains different percentage of a ceramic powder, which is produced as a waste material by Czech company Heluz cihlářský průmysl, v.o.s. This waste material is produced by grinding of calibrated ceramic thermal insulation blocks. The slaked lime CL $90 \mathrm{~S}$ is produced by the Czech company Črtovy schody a.s. Portland cement 42.5 R [4] was used in the amount of $10 \%$ of essential binders.

The blended cement-lime plaster labelled as the VCR was used as the reference. Modified plasters with an increasing content of ceramics were labelled as VC1 to VC6 (Table 1). The consistency of mortars was tested by standard flow test $(160 / 160 \mathrm{~mm})$ [5]. The ratio of water and dry substances was around 0.22 and was set by flown properties on fresh mortar mixtures.

Table 1: The composition of studied plasters

\begin{tabular}{lcccccccc}
\hline & & & & \multicolumn{5}{c}{ Sand [kg] } \\
Material & Lime [kg] & Cement $[\mathrm{kg}]$ & $\begin{array}{c}\text { Brick } \\
\text { ash [kg] }\end{array}$ & & $0.3-0.8$ & $0.6-1.2$ & $1.0-4.0$ & w/d \\
\hline VCR & 5.63 & 0.63 & 0.00 & 6.25 & 6.25 & 6.25 & 0.220 \\
VC1 & 5.34 & 0.59 & 0.31 & 6.25 & 6.25 & 6.25 & 0.241 \\
VC2 & 5.06 & 0.56 & 0.63 & 6.25 & 6.25 & 6.25 & 0.248 \\
VC3 & 4.50 & 0.50 & 1.25 & 6.25 & 6.25 & 6.25 & 0.224 \\
VC4 & 3.94 & 0.44 & 1.88 & 6.25 & 6.25 & 6.25 & 0.224 \\
VC5 & 3.38 & 0.38 & 2.50 & 6.25 & 6.25 & 6.25 & 0.223 \\
VC6 & 2.81 & 0.31 & 3.13 & 6.25 & 6.25 & 6.25 & 0.200 \\
\hline
\end{tabular}

\section{EXPERIMENTAL METHODS}

\subsection{Basic physical properties}

Tested basic physical properties were bulk density $\rho\left[\mathrm{kg} \mathrm{m}^{-3}\right]$, matrix density $\rho_{\text {mat }}\left[\mathrm{kg} \mathrm{m}^{-3}\right]$ and open porosity $\psi_{0}[\%]$. These properties were measured using the water vacuum saturation method [6] and helium pycnometry.

The water vacuum saturation was measured on samples of dimensions $50 \times 50 \times 50 \mathrm{~mm}$. Samples were dried at $80^{\circ} \mathrm{C}$ and weighed. Afterward, they were vacuum saturated by water, 
it means that samples were given to the evacuated desiccator for at least 48 hours. Then they were weighed again in the saturated state and also their mass under water level with the help of Archimedes scales was determined.

The matrix density was determined also by helium pycnometry. This experiment was carried out by the device "Pycnomatic ATC" produced by company Thermo. The device has an analogous principle as classic porosimetry.

\subsection{Pore system}

The pore system characteristics were measured by mercury intrusion porosimetry. This experiment was carried out by the devices "Pascal 140 and 440". The results are cumulative and incremental pore-size distribution curves.

\subsection{Mechanical properties}

Mechanical properties are measured on the prisms of dimensions $40 \times 40 \times 160 \mathrm{~mm}$. The compressive and bending strength were determined according to the standard [7]. The bending strength was determined by the device "MTS 100". The measurement was made by the classic tree-point burdening. The distance between supports was $100 \mathrm{~mm}$. The compressive strength was determined by the device "EU 40" and on half-beams from the bending strength measurement.

\subsection{Thermal properties}

The thermal conductivity $\lambda\left[\mathrm{Wm}^{-1} \mathrm{~K}^{-1}\right]$ and specific heat capacity $c\left[\mathrm{Jkg}^{-1} \mathrm{~K}^{-1}\right]$ were determined by the device ISOMET 2114 - Applied Precision. ISOMET 2114 [8] is a portable and nonstationary device. Its measurement is based on the analysis of the temperature response of the analysed material to heat flow impulses. Measurement was done on the samples with dimensions of $70 \times 70 \times 70 \mathrm{~mm}$ depending on moisture content.

\section{EXPERIMENTAL RESULTS}

\subsection{Basic physical properties}

In Table 2 the final values of basic physical properties measured by the water vacuum saturation method are given. For comparison, these properties were also measured by the helium pycnometry (Table 3).

The vacuum saturation method reported somewhat lower values of porosity since it corresponds to open porosity while the results of helium pycnometry describe the total porosity. The values of bulk densities slightly increased with increasing pozzolanic admixtures, they ranged around $1700 \mathrm{~kg} \mathrm{~m}^{-3}$ in the case of all studied plaster (both water vacuum saturation and helium pycnometry). The values of the matrix densities were around $2600 \mathrm{~kg} \mathrm{~m}^{-3}$ in all studied plasters. The open porosities decreased with increasing pozzolanic admixture content. The value of the open porosity $\psi_{0}$ of plaster VC6 in comparison with plaster VCR increased by $10 \%$ (water vacuum saturation and helium pycnometer). 
Table 2: Basic physical properties of the studied plasters - water vacuum saturation.

\begin{tabular}{lccc}
\hline \multirow{2}{*}{ Material } & \multicolumn{3}{c}{ Water vacuum saturation } \\
\cline { 2 - 4 } & $\rho\left[\mathrm{kg} \mathrm{m}^{-3}\right]$ & $\rho_{\text {mat }}\left[\mathrm{kg} \mathrm{m}^{-3}\right]$ & $\psi_{0}[\%]$ \\
\hline VCR & 1697 & 2605 & 34.89 \\
VC1 & 1663 & 2549 & 34.76 \\
VC2 & 1675 & 2551 & 34.34 \\
VC3 & 1724 & 2582 & 33.21 \\
VC4 & 1722 & 2575 & 33.16 \\
VC5 & 1728 & 2583 & 33.09 \\
VC6 & 1787 & 2597 & 31.48 \\
\hline
\end{tabular}

Table 3: Basic physical properties of the studied plasters - helium pycnometer.

\begin{tabular}{lccc}
\hline \multirow{2}{*}{ Material } & \multicolumn{3}{c}{ Pycnometry } \\
\cline { 2 - 4 } & $\rho\left[\mathrm{kg} \mathrm{m}^{-3}\right]$ & $\rho_{\text {mat }}\left[\mathrm{kg} \mathrm{m}^{-3}\right]$ & $\psi_{0}[\%]$ \\
\hline VCR & 1669 & 2667 & 37.41 \\
VC1 & 1640 & 2616 & 37.31 \\
VC2 & 1663 & 2649 & 37.23 \\
VC3 & 1685 & 2683 & 37.19 \\
VC4 & 1678 & 2667 & 37.10 \\
VC5 & 1685 & 2654 & 36.52 \\
VC6 & 1764 & 2659 & 33.65 \\
\hline
\end{tabular}

\subsection{Pore system}

Figures 1 and 2 show the pore-size distribution curves of studied plasters. In these figures a growth of the pore volume and, thus, different pore distributions can be seen. The pozzolanic admixture slightly increased the volume of bigger pores. The same trend was confirmed by Naceri and Hamina in their study [9].

\subsection{Mechanical properties}

Tables 4-7 show the mechanical properties of the studied plasters. By adding the pozzolanic admixture the values of the compressive and bending strength grew up. The same trend was observed in all periods of time (28, 90, 180 and 360 days). Achieved results corresponded to the measured values of open porosity.

The values of the bending strength of material VC6 in comparison with plaster VCR increased by about 2 times in all studied periods (28, 90, 180 and 360 days). 


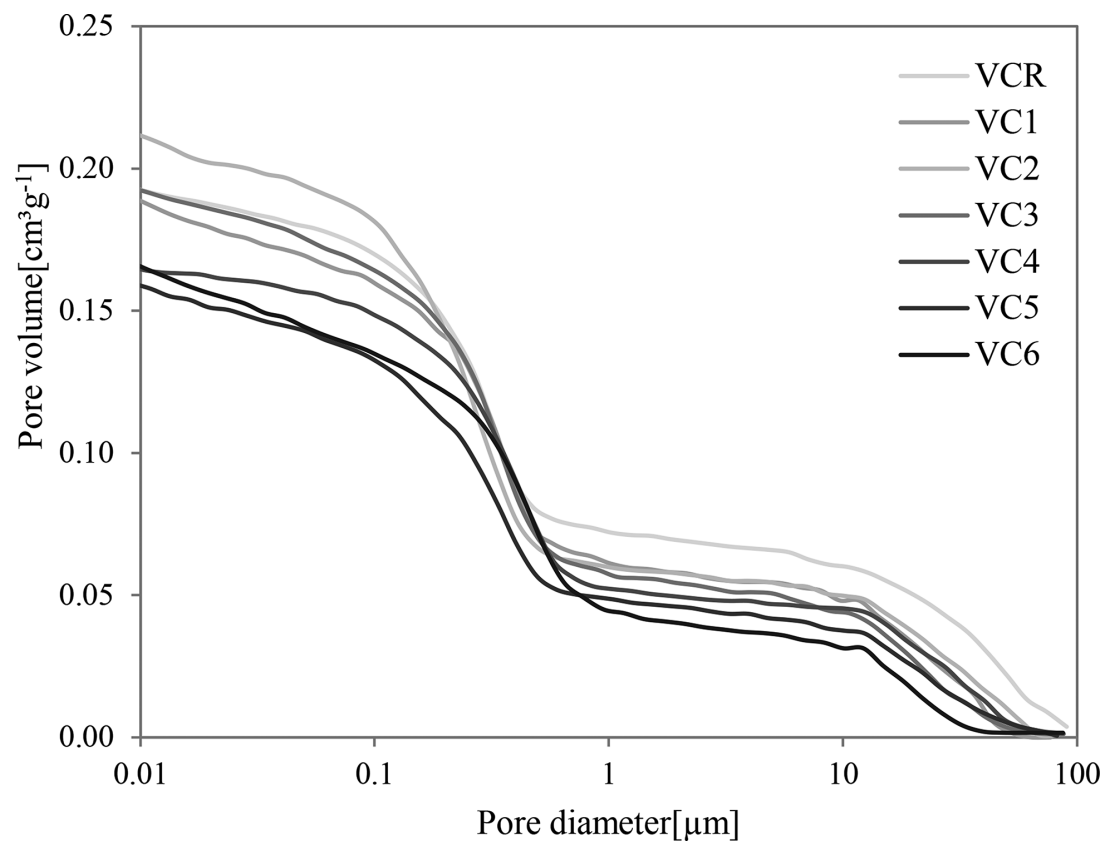

Figure 1: Incremental pore-size distribution curves.

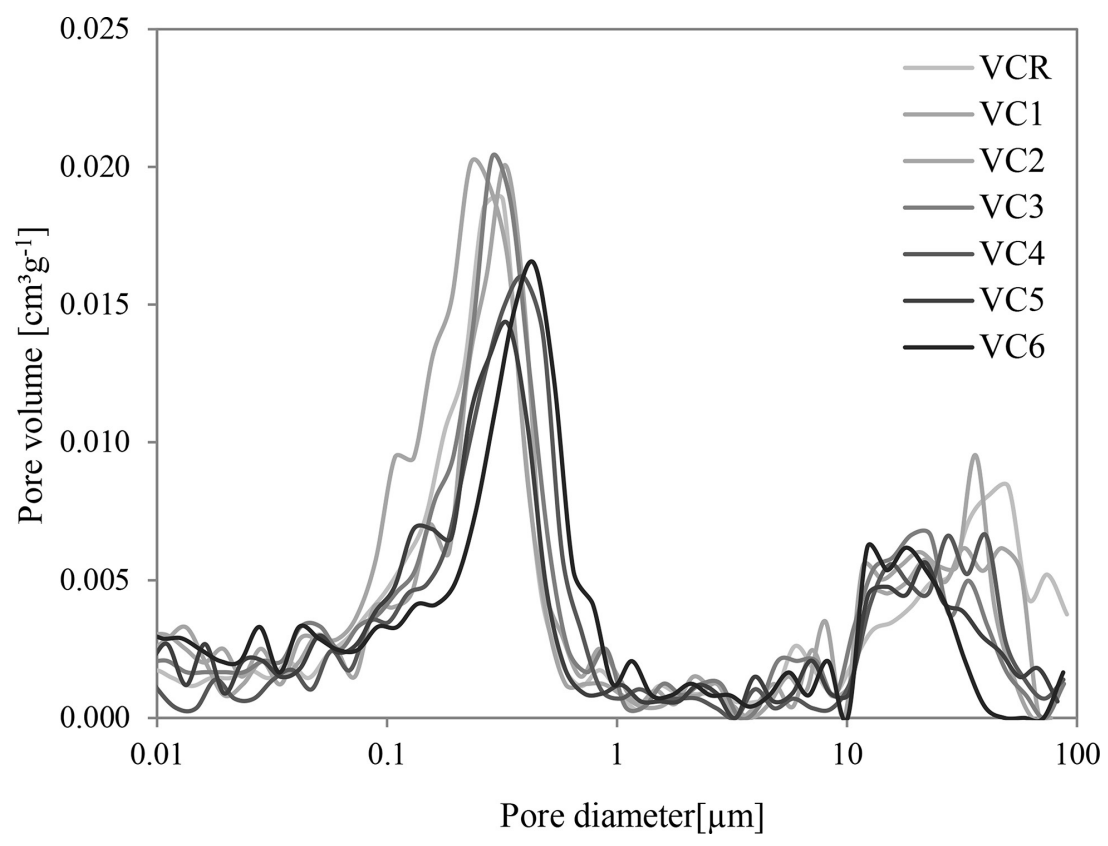

Figure 2: Cumulative pore-size distribution curves. 
Table 4: Mechanical properties of studied plasters in 28 days.

\begin{tabular}{lcc}
\hline \multirow{2}{*}{ Material } & \multicolumn{2}{c}{28 days } \\
\cline { 2 - 3 } & Bending strength [MPa] & Compressive strength [MPa] \\
\hline VCR & 0.25 & 0.60 \\
VC1 & 0.26 & 0.76 \\
VC2 & 0.29 & 0.84 \\
VC3 & 0.30 & 1.14 \\
VC4 & 0.41 & 1.34 \\
VC5 & 0.43 & 1.48 \\
VC6 & 0.52 & 1.55 \\
\hline
\end{tabular}

Table 5: Mechanical properties of studied plasters in 90 days.

\begin{tabular}{lcc}
\hline \multirow{2}{*}{ Material } & \multicolumn{2}{c}{90 days } \\
\cline { 2 - 3 } & Bending strength [MPa] & Compressive strength [MPa] \\
\hline VCR & 0.27 & 0.66 \\
VC1 & 0.27 & 0.88 \\
VC2 & 0.35 & 0.90 \\
VC3 & 0.35 & 1.26 \\
VC4 & 0.58 & 1.58 \\
VC5 & 0.58 & 1.60 \\
VC6 & 0.58 & 1.64 \\
\hline
\end{tabular}

Table 6: Mechanical properties of studied plasters in 180 days.

\begin{tabular}{lcc}
\hline \multirow{2}{*}{ Material } & \multicolumn{2}{c}{180 days } \\
\cline { 2 - 3 } & Bending strength [MPa] & Compressive strength [MPa] \\
\hline VCR & 0.27 & 0.90 \\
VC1 & 0.35 & 1.07 \\
VC2 & 0.35 & 0.95 \\
VC3 & 0.37 & 1.33 \\
VC4 & 0.40 & 1.65 \\
VC5 & 0.54 & 1.93 \\
VC6 & 0.59 & 1.96 \\
\hline
\end{tabular}


Table 7: Mechanical properties of studied plasters in 360 days.

\begin{tabular}{lcc}
\hline \multirow{2}{*}{ Material } & \multicolumn{2}{c}{360 days } \\
\cline { 2 - 3 } & Bending strength [MPa] & Compressive strength [MPa] \\
\hline VCR & 0.28 & 0.92 \\
VC1 & 0.39 & 1.16 \\
VC2 & 0.35 & 1.09 \\
VC3 & 0.42 & 1.39 \\
VC4 & 0.48 & 1.61 \\
VC5 & 0.56 & 2.07 \\
VC6 & 0.61 & 2.12 \\
\hline
\end{tabular}

The values of the compressive strength in 28 and 90 days of material VC6 in comparison with plaster VCR grew by 2.5 times. The value of compressive strength in 180 days of material VC6 in comparison with plaster VCR increased by 2.1 times and in 360 days rose by 2.3 times.

Naceri and Hamina studied use waste brick of cement in mortar. They reported an increase of mechanical properties due to the influence times [9]. A similar trend was confirmed Uchima et al. in their study use pozzolanic material (kaolinitic clay and rice husk) [10].

\subsection{Thermal properties}

Thermal parameters of the studied plasters are given in Tables 8 and 9 and Figures 3 and 4 . The reference sample VCR reached the lowest value of the thermal conductivity, while the sample VC6 achieved the highest value of the thermal conductivity (in the dry and saturated states). Similar phenomenon (improvement of thermal properties by pozzolanic

Table 8: Thermal properties of the studied materials in the dry state.

\begin{tabular}{lcc}
\hline Material & $\lambda\left[\mathrm{W} \mathrm{m}^{-1} \mathrm{~K}^{-1}\right]$ & $\mathrm{c}\left[\mathrm{J} \mathrm{kg}^{-1} \mathrm{~K}^{-1}\right]$ \\
\hline VCR & 0.699 & 939 \\
$\mathrm{VC} 1$ & 0.703 & 934 \\
$\mathrm{VC} 2$ & 0.723 & 918 \\
$\mathrm{VC} 3$ & 0.767 & 920 \\
$\mathrm{VC} 4$ & 0.780 & 904 \\
$\mathrm{VC5}$ & 0.771 & 867 \\
VC6 & 0.786 & 890 \\
\hline
\end{tabular}


Table 9: Thermal properties of the studied plasters in the saturated state.

\begin{tabular}{lccc}
\hline Material & $\mathrm{w}\left[\% \mathrm{~m}^{3} \mathrm{~m}^{-3}\right]$ & $\lambda\left[\mathrm{W} \mathrm{m}^{-1} \mathrm{~K}^{-1}\right]$ & $\mathrm{c}\left[\mathrm{J} \mathrm{kg}^{-1} \mathrm{~K}^{-1}\right]$ \\
\hline VCR & 29.97 & 2.491 & 1434 \\
$\mathrm{VC} 1$ & 28.29 & 2.289 & 1396 \\
$\mathrm{VC} 2$ & 30.09 & 2.498 & 1415 \\
$\mathrm{VC} 3$ & 29.40 & 2.565 & 1394 \\
$\mathrm{VC} 4$ & 28.95 & 2.622 & 1376 \\
$\mathrm{VC5}$ & 29.55 & 2.662 & 1352 \\
VC6 & 26.77 & 2.687 & 1333 \\
\hline
\end{tabular}

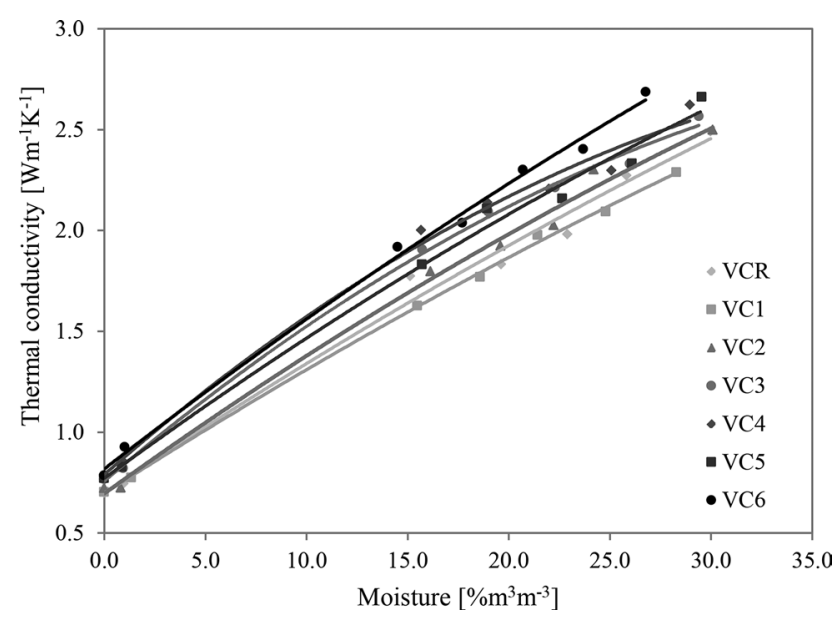

Figure 3: The thermal conductivity of plasters as function of moisture content.

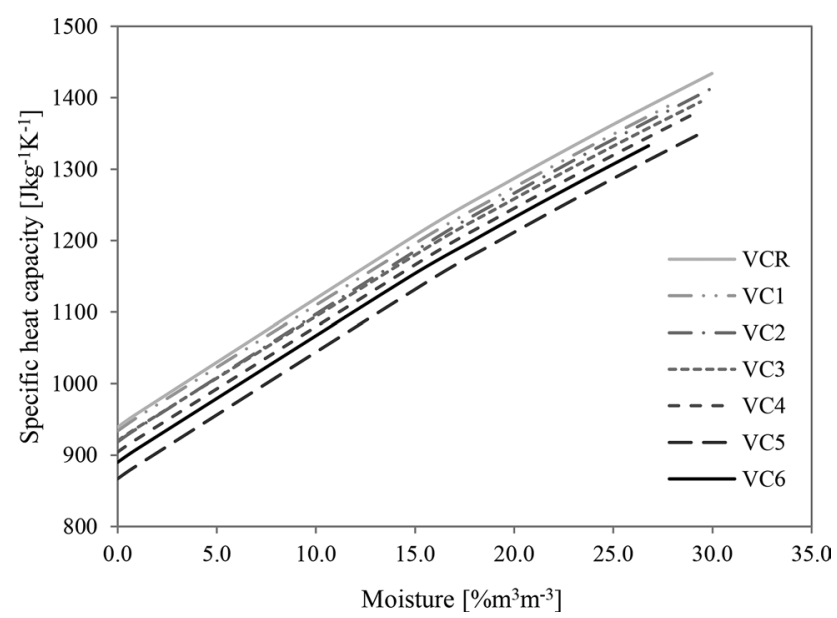

Figure 4: The specific heat capacity of studied plasters as function of moisture content. 
material addition) was confirmed by Vejmelková et al. in their plaster with Czech clay shale [11].

\section{CONCLUSION}

The effects of ceramic powder, a waste material, on the properties of lime-cement plasters were investigated in this article. The influence of the addition of the pozzolana as a supplementary cementitious material on mechanical and thermal properties of the studied materials was assessed in relation to its basic physical properties and pore structure characterization.

The goal of this paper is to find suitable proportional binder replacement in blended plaster mixtures. In this study, six plasters with replacement level from $10 \%$ to $50 \%$ of both lime and cement by ceramic brick powder are studied.

After adding a finely ground brick admixture to the plaster composition the open porosity decreased. The values of the bulk densities and open porosities were similar. By adding the pozzolanic admixture the values of the strength parameters increased. The results did correspond to the measured open porosity. Also the thermal properties were affected. The values of the thermal conductivity are slightly growing with the highest amount of the ground brick admixture.

\section{ACKNOWLEDGEMENTS}

This research has been supported in the Czech Republic by institutional support for the longterm strategic development of research organization provided by the Czech Science Foundation under project No. SGS16/199/OHK1/3T/11.

\section{REFERENCES}

[1] Rovnaníková, P., (eds), Omitky. Chemické a technologické vlastnosti, STOP, Praha, 2002.

[2] Čáchová, M., Koňáková, D., Vejmelková, E., Keppert, M., Reiterman, P. \& Černý, R., The properties of innovated mortars utilizing secondary raw material. International Conference on High Performance and Optimum Design of Structures and Materials, HPSM/OPTI 2014, WIT Transactions on the Built Environment: Ostend, pp. 49-56, 2014

[3] Čáchová, M., Vejmelková, E., Polozhiy, K. \& Černý, R., Pore system and hydric properties of two different lime plasters with finely crushed brick. 2nd International Conference on Applied Physics and Material Applications, ICAPMA 2015, Key Engineering Materials: Pattaya, 2015.

[4] ČSN EN 197-1, Cement - Part 1: Composition, specifications and conformity criteria for common cements, 2012.

[5] ČSN EN 1015-3, Methods of test for mortar for masonry - Part 3: Determination of consistence of fresh mortar (by flow table), 2000.

[6] ČSN EN 1015-10, Methods of test for mortar for masonry - Part 10: Determination of dry bulk density of hardened mortar, 2000.

[7] ČSN EN 1015:11, Determining the strength of hardened mortar bending and compressive, 2000.

[8] ISOMET, In Applied Precision (online) Ltd., 2011, Bratislava, http://www.appliedp. com/en/isomet.htm

[9] Naceri, A. \& Hamina, M.C., Use of waste brick as partial replacement of cement in mortar. Waste Management, 29(8), pp. 2378-2384, August 2009. 
[10] Uchima, J.S., Restrepo, O.J. \& Tobón, J.I., Pozzolanicity of the material obtained in the simultaneous calcination of biomass and kaolinitic clay. Construction and Building Materials, 95, pp. 414-420, July 2015.

[11] Vejmelková, E., Keppert, M., Rovnaníková, P., Keršner, Z. \& Černý, R., Application of burnt clay shale as pozzolan addition to lime mortar. Cement and Concrete Composites, 34(4), pp. 486-492, April 2012. 